\title{
Study of the Biodegradation of PLA/PBAT Films after Biodegradation Tests in Soil and the Aqueous Medium
}

\author{
Rita de Cássia Barbosa Camargo Lamparelli ${ }^{1(\mathbb{D})}$, Larissa Stieven Montagna ${ }^{(\mathbb{D})}$, Ana Paula Bernardo da \\ Silva ${ }^{1(\mathbb{D})}$, Thaís Larissa do Amaral Montanheiro ${ }^{1,2, *(\mathbb{D})}$, Ana Paula Lemes 1 (D)
}

1 Federal University of São Paulo (UNIFESP), Institute of Science and Technology, Polymer and Biopolymer Technology Laboratory (TecPBio), 330 Talim St., São José dos Campos, SP, 12231-280, Brazil; rita_lamparelli@hotmail.com (R.C.B.C.L.), larissa.s.montagna@gmail.com (L.S.M.), anapaula.silva.sjc@hotmail.com (A.P.B.S.), tlamontanheiro@gmail.com (T.L.A.M.), aplemess@gmail.com (A.P.L.);

2 Laboratory of Plasmas and Processes, Technological Institute of Aeronautics, Praça Marechal Eduardo Gomes, 50 - Vila das Acacias, São José dos Campos, SP, 12228-900, Brazil; tlamontanheiro@ gmail.com (T.L.A.M.);

* Correspondence: tlamontanheiro@gmail.com;

Scopus Author ID 56708696600

Received: 23.02.2021; Revised: 29.04.2021; Accepted: 5.04.2021; Published: 26.04.2021

\begin{abstract}
The intense consumption of conventional plastics has been generating a series of problems for nature due to the accumulation of municipal solid waste because of its difficult degradation. Therefore, the use of biodegradable polymers becomes a good option to minimize these effects. Poly (lactide acid)/poly(butylene adipate-co-terephthalate) (PLA/PBAT) is a biodegradable blend that can be used mainly in applications that have a short shelf life. So, it is important to know the total biodegradation time of this blend. For this reason, PLA/PBAT films $(1.5 \times 1.5 \times 0.15 \mathrm{~cm})$ were produced by thermal compression molding to be subjected to biodegradation tests in soil and aqueous medium for 180 days. The films were characterized by visual analysis, weight loss measurements, differential scanning calorimetry (DSC), Fourier transforms infrared spectroscopy (FT-IR), contact angle, and scanning electron microscopy (SEM). DSC showed an increase of $0.7 \%$ in PLA crystallinity subjected to the aqueous medium, while FT-IR showed a reduction in the bands at $1710 \mathrm{~cm}-1$ and $1100 \mathrm{~cm}-1$, as a result of hydrolysis for both methodologies. The blend's hydrophilic character was increased after both degradation processes, presenting a reduction of $34.5 \%$ in the contact angle after biodegradation in soil. From the results, it was possible to conclude that PLA/PBAT films did not degrade completely, as expected, but showed signs that indicated the beginning of the degradation. The degradation was more effective in the aqueous medium.
\end{abstract}

Keywords: polymer blend; poly (lactide acid); poly (butylene adipate-co-terephthalate); biodegradation in soil; biodegradation in aqueous medium.

(C) 2021 by the authors. This article is an open-access article distributed under the terms and conditions of the Creative Commons Attribution (CC BY) license (https://creativecommons.org/licenses/by/4.0/).

\section{Introduction}

It is increasingly known the importance that conventional plastics have in lives once they bring more comfort and practicality. Their excellent physical and barrier properties, ease of manufacturing, and low production costs have made these materials useful in almost all fields of applications [1]. However, despite these benefits, as a result of this intense consumption, several environmental problems can be caused, mainly due to the accumulation of packaging waste from non-biodegradable polymers, once they take a long period to decompose completely [1-3]. As a result, a large part of this waste accumulates in inappropriate places or is destined to open places, without proper treatment of leachate and gas collection, 
which can cause problems for human health and the environment [4, 5]. Many works report these damages caused by leachate percolation to the people and nature that live and consume this groundwater [6-9].

An environmentally-friendly alternative that has been gaining great visibility to minimize environmental problems is biodegradable polymers. Most of these polymers undergo hydrolytic and enzymatic degradation causing the polymer chains to break [10]. Their use is beneficial for the environment because the final products of biodegradable polymers are usually $\mathrm{CO}_{2}, \mathrm{CH}_{4}$, water, inorganic compounds, or biomass [11].

So, due to biodegradability, there is a great expectation about the growth in these products' consumption. According to the European Bioplastics Association, in cooperation with the research institute nova-Institute [12], the production capacity of bioplastics in 2019 was 2.1 million tons, and it is expected that this capacity is set to increase reaching around 2.4 million tons in 2024.

Some of the most well-known bioplastics used in the market are poly (lactide acid) (PLA) and poly (butylene adipate-co-terephthalate) (PBAT). PLA has great biodegradability, processability, and attractive low cost [10]. It is aliphatic thermoplastic polyester, and it is derived from renewable sources, such as sugar, corn, potatoes, cane, etc. [13]. It can be used to produce packaging in general $[10,13,14]$, for textile $[10,13]$ and biomedical $[10,14,15]$ sector. However, it is a material very brittle [16], and for this reason, it is often used with another biodegradable polymer, as poly(3-hydroxybutyrate-co-3-hydroxyvalerate) (PHBV) [17], polycaprolactone (PCL) [18, 19], PBAT [20-23] and others. The case of PBAT, which was used in the present study, is aliphatic-aromatic co-polyester derived from fossil-based resources, and it is obtained by poly-condensation between butanediol, adipic acid, and terephthalic acid [1, 24, 25]. PBAT has excellent mechanical properties and good biodegradability and is used to produce plastic packaging and mulch films [24, 26, 27].

PLA/PBAT is a biodegradable blend that was developed to improve some properties. Many studies have shown that PLA/PBAT blending can promote several improvements, such as flexibility and better processability, without, theoretically, compromising biodegradability $[1,28]$. Even presenting their biodegradability as main characteristics, these biopolymers, mainly PLA, present a slower biodegradation rate in soil than other biopolymers, such as PHBV and PCL. Biodegradation occurs due to the specific presence of enzymes that degrade PLA and are excreted by some microorganisms. What hinders the biodegradation process directly in the soil is that these microorganisms are found in lesser amounts in this medium than microorganisms that degrade other biodegradable polyesters [29-32]. But the process of biodegradation of the polymer and the blend occurs, as can be seen in the works of the literature $[30,33,34]$.

Tabasi and Ajji [35] studied selective degradation of biodegradable PLA/PHB/PBAT blends in simulated laboratory composting, and the authors explain that the disintegration of blends can be different from neat materials. Weng et al. [36] also realized that the degradation of blends of PLA/PBAT in the soil could be slower than neat PLA, even without noticing a difference in the chemical structure.

For this, there are several types of laboratory tests using different types of environmental compartments (such as soil, compost, and aqueous medium) for the assessment of polymer biodegradation $[13,14]$. These tests are performed in the laboratory to simulate ideal conditions of temperature, moisture, and oxygen to measure the degree of intrinsic biodegradability of these materials [37]. 
The vast majority of biodegradation studies of PLA and PBAT are related to composting conditions [34, 35, 38-40] and few about biodegradation under soil [30, 33] and medium aqueous conditions [41]. The number of works is even lower when it comes to the PLA/PBAT blend in different biodegradation conditions. The literature reports only a few works about under conditions of biodegradation in soil.

Weng et al. [36] studied the biodegradation of PLA, PBAT, and the blend of PBAT/PLA (40/60), in real conditions of biodegradation in soil and observed different degradation rates for each polymer after 4 months of degradation.

Freitas et al. [42] investigated the thermal, rheological, and morphological properties of PLA/PBAT blends (45/55) containing montmorillonite clay (MMT) and/or chain extenders (CE) after 126 days of biodegradation in soil. The authors verified that the blend without the other components' addition showed the highest amount of $\mathrm{CO}_{2}$ released and more signs of degradation compared to the other mixtures.

Palsikowski et al. [43] also studied biodegradation in soil of PLA, PBAT, and PLA/PBAT blends (25/75) and (75/25) compatibilized with a chain extender and verified that the effect of adding the chain extender was to delay the biodegradation process after 360 days.

For this reason, it is interesting to better understand the biodegradation time of this blend without the addition of another component and to know how it would react under other conditions, such as in aqueous medium conditions. Thus, a study on the biodegradation of the PLA/PBAT blend under an aqueous medium becomes important to compare it with soil conditions. In this way, this work's objective was to study the biodegradation of PLA/PBAT blend through the performance of biodegradation tests in soil and the aqueous medium.

\section{Materials and Methods}

\subsection{Materials.}

Poly (lactide acid)/poly (butylene adipate-co-terephthalate) (PLA/PBAT) was provided by Basf (Brazil) with the name ecovio ${ }^{\circledR}$. Ecovio ${ }^{\circledR}$ is a commercial blend composed of $45 \% \mathrm{wt}$ of poly(lactide acid) and 55\%wt of poly(butylene adipate-co-terephthalate) with a density range from 1.24 to $1.26 \mathrm{~g} / \mathrm{cm}^{3}$. Commercial garden-fresh soil from West Garden ${ }^{\circledR}$ (São Paulo, Brazil) was used for the biodegradation test.

\subsection{Method for obtaining PLA/PBAT films.}

PLA/PBAT films $(1.5 \times 1.5 \times 0.15 \mathrm{~cm})$ were obtained by thermal compression molding at $200{ }^{\circ} \mathrm{C}$ with a pressure of 1 ton for $3 \mathrm{~min}$, using a hydraulic press (MH Equipamentos, Brazil, model PR8HP). The average mass of the samples was $0.25 \mathrm{~g}$.

\subsection{Biodegradation tests.}

Two biodegradation tests (biodegradation in soil and aqueous medium) were carried out on PLA/PBAT films for 180 days. At the end of both biodegradation tests, the films were washed thoroughly with distilled water to remove adhered material in their surfaces and dried in a vacuum oven $\left(28^{\circ} \mathrm{C} \pm 2{ }^{\circ} \mathrm{C}\right)$ for $24 \mathrm{~h}$ until constant weight. All the samples were characterized by visual analysis, weight loss measurements, differential scanning calorimetry (DSC), Fourier transformed infrared spectroscopy (FT-IR), contact angle, and scanning electron microscopy (SEM). 


\subsubsection{Biodegradation in soil.}

The soil biodegradation test was based on the methodology used by Braga et al. [44]. For the biodegradation test in soil, the films of PLA/PBAT $(n=6)$ were buried in commercial soil Falcon flasks $(50 \mathrm{~mL})$, and the humidity was controlled at $60 \%$ of the retention capacity. The amount of soil was calculated from the relation between the mass of the soil $\left(\mathrm{m}_{\mathrm{s}}\right)$ and the mass of the film $\left(\mathrm{m}_{\mathrm{f}}\right)$, according to Equations 1 and 2.

$$
\begin{aligned}
& \text { Relation }=\frac{m_{s}}{m_{f}} \\
& m_{s}=\text { Relation } \times m_{f}
\end{aligned}
$$

After that, the Falcon Flasks were placed inside an incubator (LUCADEMA Incubadora Shaker Luca-223) with a controlled temperature of $30^{\circ} \mathrm{C}\left( \pm 2^{\circ} \mathrm{C}\right)$ for 180 days.

\subsubsection{Biodegradation test in an aqueous medium.}

The biodegradation in an aqueous medium was carried out according to the methodology reported by Hong et al. [45] and Silva et al. [46]. For this biodegradation test was used the mineral salt solution containing $900 \mathrm{~mL}$ of distilled water and the following amounts of salt: $\mathrm{NA}_{2} \mathrm{HPO}_{4}(2.788 \mathrm{~g}), \mathrm{KH}_{2} \mathrm{PO}_{4}(2.385 \mathrm{~g}), \mathrm{NH}_{4} \mathrm{Cl}(0.270 \mathrm{~g}), \mathrm{MgSO}_{4} \cdot 7 \mathrm{H}_{2} \mathrm{O}(0.432 \mathrm{~g})$ and more $900 \mu \mathrm{L}$ of another solution containing $\left(\mathrm{NH}_{4}\right)_{2} \mathrm{Fe}\left(\mathrm{SO}_{4}\right)_{2} .6 \mathrm{H}_{2} \mathrm{O}(0.05 \mathrm{~g}), \mathrm{ZnSO}_{4} .7 \mathrm{H} 2 \mathrm{O}$ $(0.013 \mathrm{~g}), \mathrm{MnCl}_{2} .4 \mathrm{H}_{2} \mathrm{O}(0.013 \mathrm{~g}), \mathrm{CuSO}_{4} .5 \mathrm{H}_{2} \mathrm{O}(0.0005 \mathrm{~g}), \mathrm{Na}_{2} \mathrm{~B}_{4} \mathrm{O}_{7} .10 \mathrm{H}_{2} \mathrm{O}(0.0005 \mathrm{~g})$ in 250 $\mathrm{mL}$ of $1 \mathrm{M} \mathrm{HCl}$ solution. Both solutions were autoclaved for $20 \mathrm{~min}$ at $121^{\circ} \mathrm{C}$.

To prepare the microbial inoculum, it was necessary to extract the microorganisms present in commercial soil to add to a culture medium. It was added $280 \mathrm{~g}$ of vegetal soil and $400 \mathrm{~mL}$ of water in a flask. After that, the mixture was stirred and remained for $1 \mathrm{~h}$ at rest. Then, the system was filtered to remove suspended particles. The proportion used was $40 \%$ $(\mathrm{v} / \mathrm{v})$ of filtrate solution and $60 \%(\mathrm{v} / \mathrm{v})$ of culture medium containing glucose $(0.3 \mathrm{~g})$, peptone $(0.3 \mathrm{~g})$, yeast extract $(0.3 \mathrm{~g})$, and $300 \mathrm{~mL}$ of distilled water which had also been autoclaved for $20 \mathrm{~min}$ at $121^{\circ} \mathrm{C}$.

The initial concentration of microbial cells implanted in test solutions was controlled at around $50 \mathrm{mg}$ of dry cell weight per liter of the test solution, so $1.9 \mathrm{~mL}$ of the microbial inoculum was added. The number of microorganisms in the reactional medium affects the rate of biodegradation of samples. So, the authors determined the mass concentration of dry cells in the microbial suspension because it was a fast and available method to quantify the number of microorganisms, which compares with other works. The same methodology was used by Silva et al. (2019) [46] for the biodegradation tests. The average mass of the films was $0.25 \mathrm{~g}$.

After all, in Falcon flasks ( $50 \mathrm{~mL}$ ), was added $20 \mathrm{~mL}$ of mineral salt solution, $1.9 \mathrm{~mL}$ of microbial inoculum, and samples of PLA/PBAT $(n=6)$. All Falcon flasks were left semiclosed for gas exchange inside an incubator (LUCADEMA - Incubadora Shaker Luca223) under stirring at $120 \mathrm{rpm}$ and $30^{\circ} \mathrm{C}$. The biodegradation time was 180 days. 


\subsection{Analytical characterization.}

2.4.1. Visual analysis.

Images of PLA/PBAT films were taken using a photographic camera (Sony ${ }^{\circledR}$ Cybershot DSC-HX200V) before and after biodegradation tests in soil and the aqueous medium to analyze surface degradation after these biodegradation tests.

\subsubsection{Weight loss.}

PLA/PBAT films ( $n=6)$ were weighed on an analytical balance (Marte - AY200) before and after both biodegradation tests. The percent weight loss was determined using Equation 3.

$$
W t . \operatorname{loss}(\%)=\frac{W 0-W f}{W 0} X 100
$$

Where Wo is the initial weight and $\mathrm{W} f$ is the final weight after the biodegradation test. The test was performed in triplicate; the weight loss was calculated by their average.

\subsubsection{Differential scanning calorimetry (DSC).}

Differential scanning calorimetry analyses (DSC) were performed on Netzsch equipment (Phoenix ${ }^{\circledR}$ DSC 2014 F1). Approximately $10 \mathrm{mg}$ of each sample was dried and placed into aluminum pans. After that, samples were heated with a heating rate of $10{ }^{\circ} \mathrm{C} \mathrm{min}{ }^{-1}$ from $25^{\circ} \mathrm{C}$ to $200{ }^{\circ} \mathrm{C}$, using a nitrogen atmosphere with a gas flow of $20 \mathrm{~mL} \mathrm{~min}^{-1}$. The degree of crystallinity (Xc) of the films was determined by Equation 4 (for PBAT fraction) and Equation 5 (for PLA fraction). The melting enthalpy of the hypothetically $100 \%$ crystalline

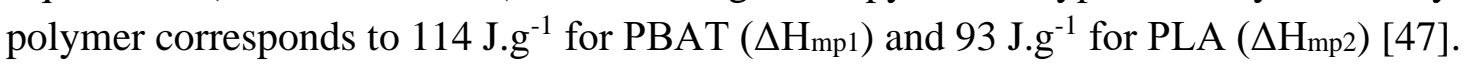

$$
\begin{aligned}
& X c 1(\%)=\frac{\Delta H m p 1}{\Delta H m P B A T 100 \% \times 0.55} \times 100 \quad \text { Eq. } 4 \\
& X c 2(\%)=\frac{\Delta H m p 2}{\Delta H m P L A 100 \% \times 0.45} \times 100 \quad \text { Eq. } 5
\end{aligned}
$$

\subsubsection{Fourier transforms infrared spectroscopy (FT-IR).}

PLA/PBAT films before and after both biodegradation tests were analyzed by Fouriertransformed infrared (FT-IR) spectroscopy in a PerkinElmer Spectrum One equipment, using universal attenuated total reflectance (UATR) from 400 to $4000 \mathrm{~cm}^{-1}$, to verify the functional groups present in the films.

\subsubsection{Contact angle.}

PLA/PBAT films were submitted to measurements of contact angle, using an advanced goniometer (Ramé-Hart, mod. 500), before and after both biodegradation tests $(n=4)$. The wetting liquid was distilled water with the sessile drop method $\left(1.0 \mu \mathrm{L}, 25^{\circ} \mathrm{C}\right)$. Then, the average of four measurements was calculated to verify the wettability of the films.

\subsubsection{Scanning electron microscopy (SEM).}

The surface morphology of PLA/PBAT films was observed by Inspect S50 (FEI Company ${ }^{\circledR}$ microscope), operated at $7.5 \mathrm{keV}$ before and after biodegradation in soil and the aqueous medium. The films were fixed on aluminum stubs and coated with gold. 


\section{Results and Discussion}

\subsection{Visual analysis.}

Figure 1 shows the macroscopic visual analysis of PLA/PBAT films at the initial time, after biodegradation in soil and aqueous medium for 180 days. At the initial time (Figure 1A), it is possible to see that the film presents a smooth white surface. However, after biodegradation in soil (Figure 1B), the films became a little rough and with yellow spots on their surfaces. In contrast, after biodegradation in the aqueous medium (Figure 1C), the films presented only a rougher aspect.

Palsikowski et al. [43] studied the biodegradation of PLA/PBAT(75/25) and PLA/PBAT(25/75) blends and observed the yellowing of the samples and some deformations, followed by breaks only after 180 days, being more effective in the blend with higher amount of PBAT. The authors justify the better resistance of the blend PLA/ PBAT (75/25) because it has a higher amount of PLA and a glass transition temperature ( $\mathrm{Tg}$ ) above room temperature, hindering its biodegradation.

In the case of biodegradation in the aqueous medium, the effect of biodegradation was also very moderate. Moreover, the authors explain that low degradation can occur because the laboratory conditions are not as aggressive as the external environment, mainly concerning temperature [43].

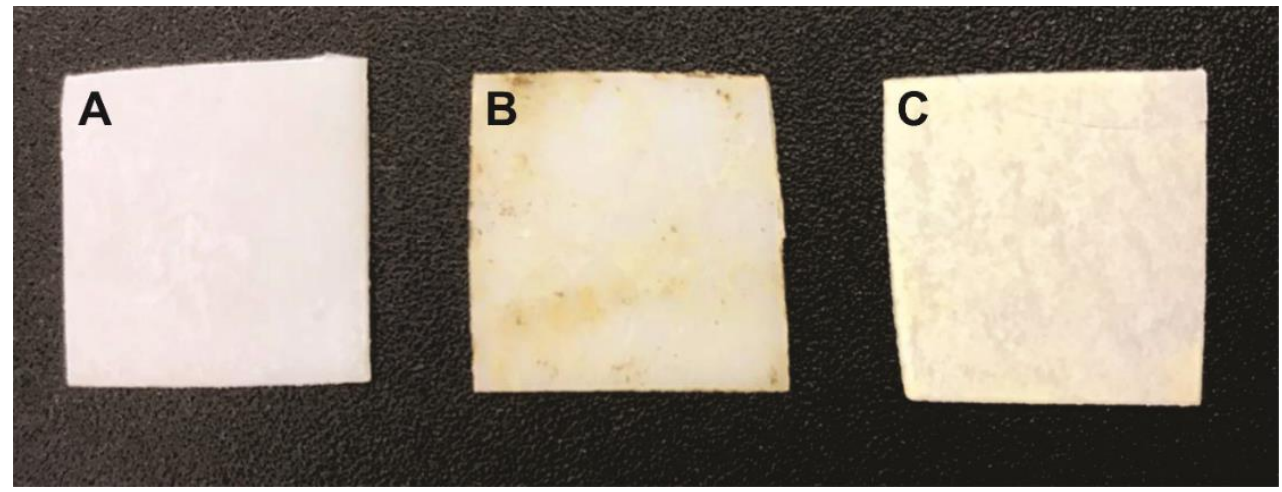

Figure 1. PLA/PBAT films: at the initial time (A), after biodegradation in soil (B), and in the aqueous medium (C).

\subsection{Weight loss.}

Figure 2 shows the weight loss percentage of PLA/PBAT films after exposure to the biodegradation test in soil and aqueous medium for 180 days. The result presented is lower than expected for a biodegradable material. According to ASTM 6400, [48] for a polymer to be considered biodegradable, the organic carbon present in the film should have a degradation of approximately $90 \%$ in 180 days. What happened was an increase in the weight of the films after both biodegradation tests. The increase in the weight of the films may be related to water's presence, characteristic of the hydrolysis process of biodegradation in an aqueous medium, necessary for the biodegradation of the material. According to Rydz et al. [49], at the beginning of biodegradation, due to hydrolytic degradation, the weight loss slowly decreases, which may be the case of these studied films. Furthermore, it was possible to observe the effect of biodegradation, possibly due to the formation of colonies of microorganisms on the surface of the films, mainly in the biodegradation in the aqueous medium. The presence of 
microorganisms is important for the consumption of hydrolysis products, promoting biodegradation [42].

After the biodegradation in soil, the PLA/PBAT films presented an increase of $\sim 0.7$ $\mathrm{wt} \%$, while after the biodegradation in the aqueous medium, the PLA/PBAT films presented an increase of $\sim 1.4 \mathrm{wt} \%$, indicating that biodegradation in soil, possibly will be faster in longer periods of degradation, due to the action of microorganisms present in the soil, causing the breakdown and/or consumption of the PBAT chains [40]. Furthermore, according to Kijchavengkul et al. [40], the biodegradation of PBAT is caused mainly by microbial degradation and hydrolysis, as the BA structure is more susceptible to hydrolysis than was the BT structure; that is, the non-crystalline portion of PBAT can be more readily biodegraded than the crystalline portion.

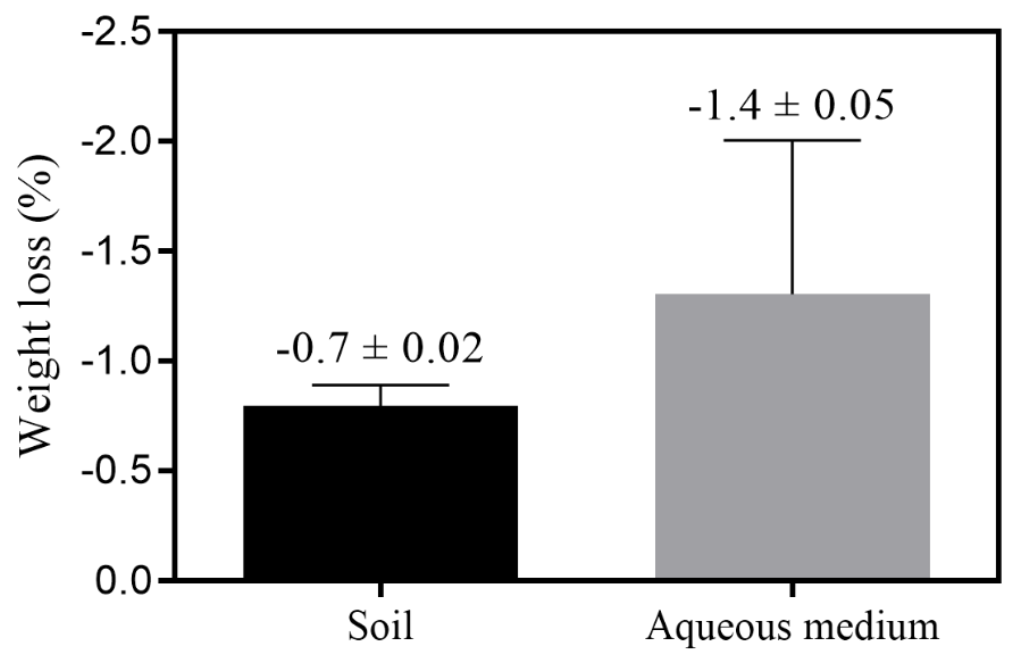

Figure 2. Weight loss (\%) of PLA/PBAT films after biodegradation in soil and in aqueous medium for 180 days.

\subsection{Differential scanning calorimetry.}

Figure 3 shows the DSC thermograms of PLA/PBAT films before and after biodegradation tests in soil and aqueous medium for 180 days, and Table 1 summarizes $\mathrm{Tg}$, cold crystallization (Tcc), melting temperature $(\mathrm{Tm})$, and degree of crystallinity $\left(\mathrm{X}_{\mathrm{c}}\right)$ for PLA/PBAT films.

It is noted that the films, at the initial time, presented $\mathrm{Tg}$ and $\mathrm{Tcc}$ at $59.9^{\circ} \mathrm{C}$ and $88^{\circ} \mathrm{C}$, respectively, both referring to the PLA and two melting peaks at approximately $151.6^{\circ} \mathrm{C}$ for PBAT and $166^{\circ} \mathrm{C}$ for PLA.

Freitas et al. [42] studied biodegradation in soil of PLA/PBAT blends (45/55) and also observed during the DSC analysis before biodegradation test, the occurrence of two melting peaks related to PLA and PBAT with Tm's similar to this work. Musioł et al. [50] also observed the occurrence of these two melting peaks, but the Tm's were close to $145^{\circ} \mathrm{C}$ for PBAT and $150{ }^{\circ} \mathrm{C}$ for PLA. However, the blend studied by the authors was composed of $40 \%$ PLA and $60 \%$ PBAT, different from the present study that used the $45 / 55$ ratio.

After the biodegradation tests, it was possible to observe that there was a slight change in the thermal behavior of the films. After the biodegradation in soil, PLA/PBAT films presented $\mathrm{Tg}$ at $62.5^{\circ} \mathrm{C}\left(+2.6^{\circ} \mathrm{C}\right)$, Tcc at $87.1^{\circ} \mathrm{C}\left(-0.9^{\circ} \mathrm{C}\right)$, and two Tm's at $151.6^{\circ} \mathrm{C}\left(0.0^{\circ} \mathrm{C}\right)$ for PBAT and at $164.8^{\circ} \mathrm{C}\left(-1.2^{\circ} \mathrm{C}\right)$ for PLA, when comparing with the film at the initial time; 
while after the biodegradation in aqueous medium the PLA/PBAT films presented $\mathrm{Tg}$ at 61.8 ${ }^{\circ} \mathrm{C}\left(+1.9{ }^{\circ} \mathrm{C}\right)$, Tcc at $84.4{ }^{\circ} \mathrm{C}\left(-3.6{ }^{\circ} \mathrm{C}\right)$ and two Tm's at $150.3{ }^{\circ} \mathrm{C}\left(-1.3{ }^{\circ} \mathrm{C}\right)$ for PBAT and $164.1^{\circ} \mathrm{C}\left(-1.9^{\circ} \mathrm{C}\right)$ for PLA, compared with initial time films.

Although the literature reports that a decrease in Tg is expected over time [30], a small increase was observed in both biodegradation tests. This fact may be related to the breakdown of the largest chain segments of the amorphous phase at the beginning, which is more easily bio-assimilated or crystallized due to less restriction by the crystalline phase. However, the remaining segments of the amorphous phase are smaller and more difficult to break, increasing $\mathrm{Tg}$ [43]. Besides that, it is worth noting that the samples were exposed to biodegradation under conditions of lower temperatures than that adopted in composting simulations $\left(58^{\circ} \mathrm{C}\right)$, which may explain a longer delay for the degradation process [51].

Regarding $\mathrm{X}_{\mathrm{c}}$ values, it was observed that after the biodegradation in soil, the crystallinity of PLA decreased $13.8 \%$ and for PBAT increased $1 \%$, while after the biodegradation in the aqueous medium, there was an increase of $0.7 \%$ for PLA and a reduction of $0.2 \%$ for PBAT. After biodegradation in the aqueous medium, there was an increase in PLA crystallinity, indicating that PLA hydrolysis occurred, being responsible for reducing the size of the chain segments in the amorphous region. So, as degradation occurs, the greater the mobility of these chains, increasing their crystallinity [43, 52].

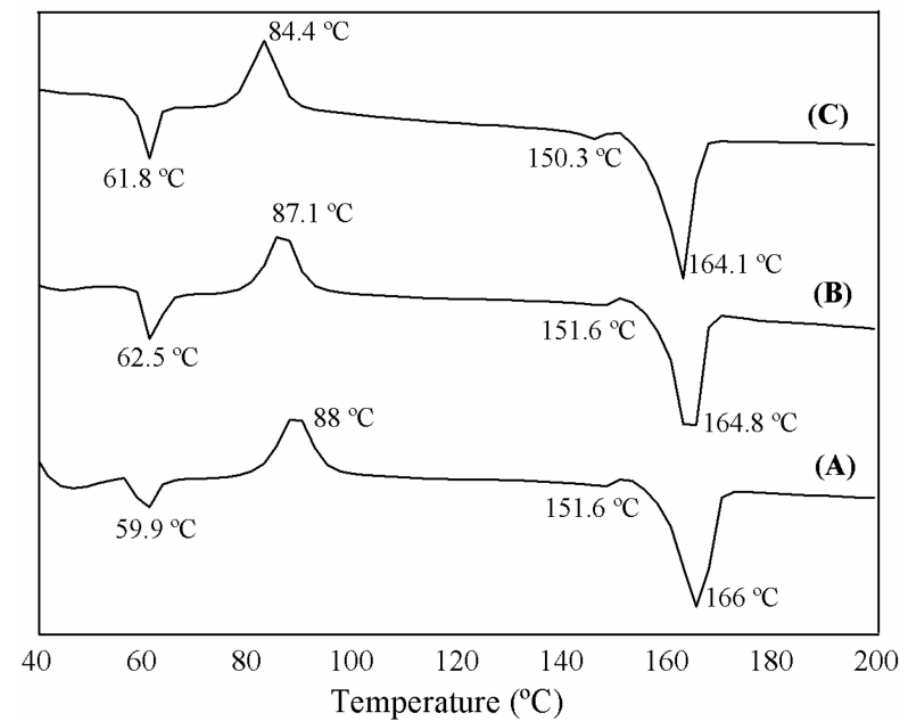

Figure 3. DSC thermogram of PLA/PBAT films at the initial time (A), after biodegradation in soil (B) and in an aqueous medium (C) for 180 days.

Table 1. Thermal properties of PLA/PBAT films at the initial time, after biodegradation in soil and in aqueous medium for 180 days.

\begin{tabular}{l|l|l|l|l|l|l|l}
\multirow{2}{*}{ Sample } & \multicolumn{2}{|l|}{$\mathbf{T g}\left({ }^{\circ} \mathbf{C}\right)$} & \multicolumn{2}{l|}{ Tcc $\left({ }^{\circ} \mathbf{C}\right)$} & \multicolumn{2}{l}{ Tm $\left({ }^{\circ} \mathbf{C}\right)$} & \multicolumn{2}{l}{ Xc $(\%)$} \\
\cline { 2 - 8 } & PLA & PBAT & PLA & PLA & PBAT & PLA & PBAT \\
\hline Initial time & 59.9 & - & 88.0 & 166.0 & 151.6 & 81.3 & 1.8 \\
\hline After biodegradation in Soil & 62.5 & - & 87.1 & 164.8 & 151.6 & 67.5 & 2.8 \\
\hline After biodegradation in Aqueous Medium & 61.8 & - & 84.4 & 164.1 & 150.3 & 82.0 & 1.6
\end{tabular}

\subsection{Fourier transform infrared spectroscopy (FT-IR).}

Figure 4 shows the FT-IR spectrum, behavior of the functional groups of PLA/PBAT films at the initial time, after biodegradation in soil and the aqueous medium for 180 days. At the initial time, it is possible to identify different peaks, such as $3000-2800 \mathrm{~cm}^{-1}$ bands related 
to $\mathrm{C}-\mathrm{H}$ deformations (symmetric and asymmetric bends), a large and intense peak, around 1750 $\mathrm{cm}^{-1}$ attributed to $\mathrm{C}=\mathrm{O}$ from ester groups, and $1267 \mathrm{~cm}^{-1}$ assigned to $\mathrm{CO}$ stretch [53].

According to Kijchavengkul et al. [40], some functional groups may show signs of degradation, such as hydroxyl $(\mathrm{OH})$ and carbonyl $(\mathrm{C}=\mathrm{O})$ groups. Therefore, hydrolysis chain scission can result in ester bonds, terminal alcohol, and carboxylic acid groups and form smaller molecules or oligomers capable of permeating out of the polymer matrix and reducing carbonyl absorption.

After both biodegradation tests, some changes were observed in the films. In the 3350 $\mathrm{cm}^{-1}$ region, an increase in $\mathrm{OH}$ groups can be seen, especially for biodegradation in the aqueous medium [40]. These changes are related to the bond scission, which is a characteristic of the hydrolysis process [54], or to adsorbed water, which would justify the weight increase reported, especially after biodegradation aqueous medium [55-57]. A small reduction in the bands at $1710 \mathrm{~cm}^{-1}$, corresponding to stretching vibrations of $-\mathrm{C}=\mathrm{O}$, and at around $1100 \mathrm{~cm}^{-1}$, attributed to -C-O groups can be noted, also as a result of hydrolysis [40, 58, 59].

Palsikowski et al. [43] also report small variations by FT-IR analysis after biodegradation test in the soil after 360 days of the PLA/PBAT blend. The authors explain that this degradation is very complex and depends on the environment in which it occurs.

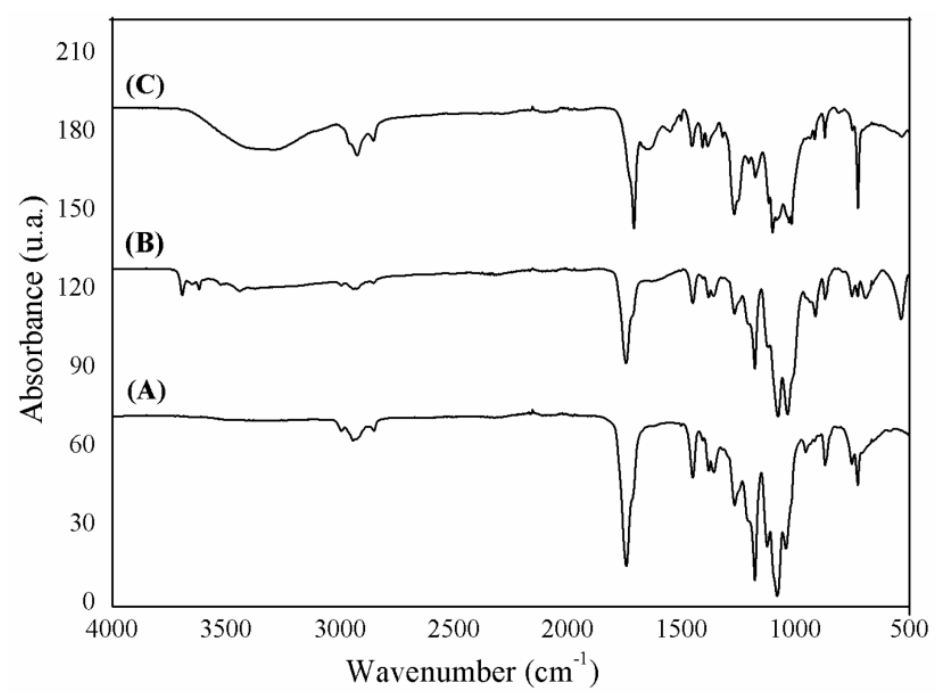

Figure 4. FT-IR spectrum of PLA/PBAT films at the initial time (A), after biodegradation in soil (B) and in an aqueous medium (C), for 180 days.

\subsection{Contact angle.}

Figure 5 shows the contact angle for PLA/PBAT films at the initial time and after biodegradation in soil of 180 days. Unfortunately, it was not possible to measure the films' contact angle after biodegradation in the aqueous medium due to the greater degradation of the films, greatly increasing hydrophilicity and making measurement impossible. After biodegradation in the aqueous medium, the contact angle for samples was close to zero, meaning a complete spreading of the water drop on the sample [60].

PLA/PBAT films presented at the initial time an average contact angle of $70.4^{\circ}$, indicating hydrophilic character since they have a contact angle less than $90^{\circ}$ [61]. After biodegradation in soil, it was observed that there was a decrease in the contact angle, which means that the hydrophilic character of the PLA/PBAT films increased. PLA/PBAT films reduced about $34.5 \%\left(-24.3^{\circ}\right)$ after biodegradation in soil when compared at the initial time. 
According to Schusser et al. [62], a decrease in the contact angle occurs mainly due to increased mobility and as the sample gets rougher.

Kalita et al. [18] verified the biodegradation of PLA/Polycaprolactone (PCL)/microcrystalline cellulose (MCC) polyblends under composting conditions. The authors explain that the increase in hydrophilicity occurs due to the formation of new oligomeric components on the films' surface. Besides, the change in wettability behavior is also responsible for the formation of biofilm.

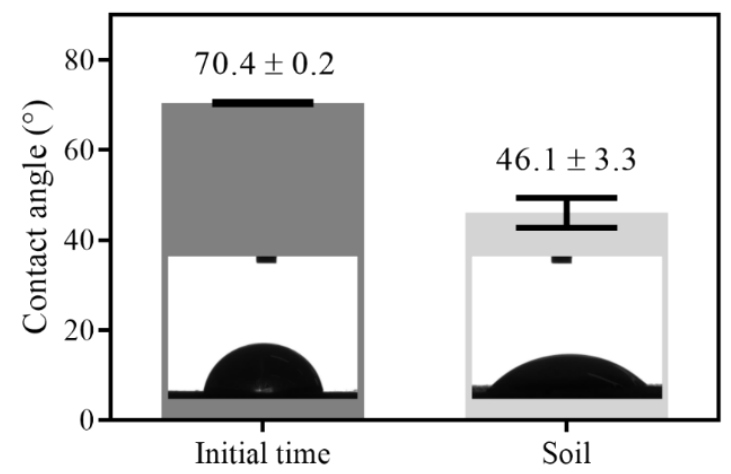

Figure 5. Contact angle of PLA/PBAT films at the initial time and after biodegradation in soil for 180 days.

\subsection{Scanning electron microscopy (SEM).}

SEM micrographs of PLA/PBAT films at the initial time, after biodegradation in soil and the aqueous medium for 180 days are shown in Figure 6. At the initial time, the films of PLA/PBAT had a smooth and homogenous surface, which can be attributed to the PBAT morphology, which has a ductile fracture surface, characteristics of the elastomeric nature [1, 63].

However, after the biodegradation tests, the surface became rougher, especially after biodegradation in the aqueous medium, but without the presence of cracks or cavities. This change on the surfaces could be traces of soil, mineral deposits, or the formation of biofilms [64, 65]. Bonilla et al. [41] studied biodegradability in aquatic systems in materials such as chitosan, PBAT, and high-density polyethylene (HDPE), also noted the presence of colonies on the surface of the PBAT.

The same behavior was seen by Olewnik-Kruszkowska et al. [66] on the surface of PLA, PLA-based composites of montmorillonite or Nanofil2 with and without the addition of poly ( $\varepsilon$-caprolactone), as a compatibilizing agent, after biodegradation in different environments, such as in soil, composting, and in water.

Moura et al. [67] explain that biodegradation occurs preferentially in the amorphous regions of the polymer since they have greater mobility, favoring the accessibility of microorganisms. Such microorganisms, like fungi, can use polymers as a source of energy from the source of carbon and electrons [68].

\section{Conclusions}

This study showed how the PLA/PBAT films behaved after 180 days of biodegradation in soil and the aqueous medium. The results indicated that the films did not completely degrade at the end of that period and that both biodegradation tests showed very similar results. They showed signs that the degradation was occurring, mainly due to the presence of water, characteristic of the hydrolysis process, and the increase of roughness on the surface of the 
films, possibly due to the presence of biofilm, traces of soil, or mineral deposits. However, we believe that the biodegradation was initiated, even in a small proportion, due to the changes observed in the samples as a whole, not individually. It was expected that this process would be faster, mainly because the film is composed of two biodegradable polymers, PLA and PBAT. So, it can be concluded that the 180-day time for the biodegradation tests of PLA/PBAT films was not enough. Thus, the films would have to be exposed for a longer time to biodegradation tests in soil and aqueous media for complete biodegradation to occur.
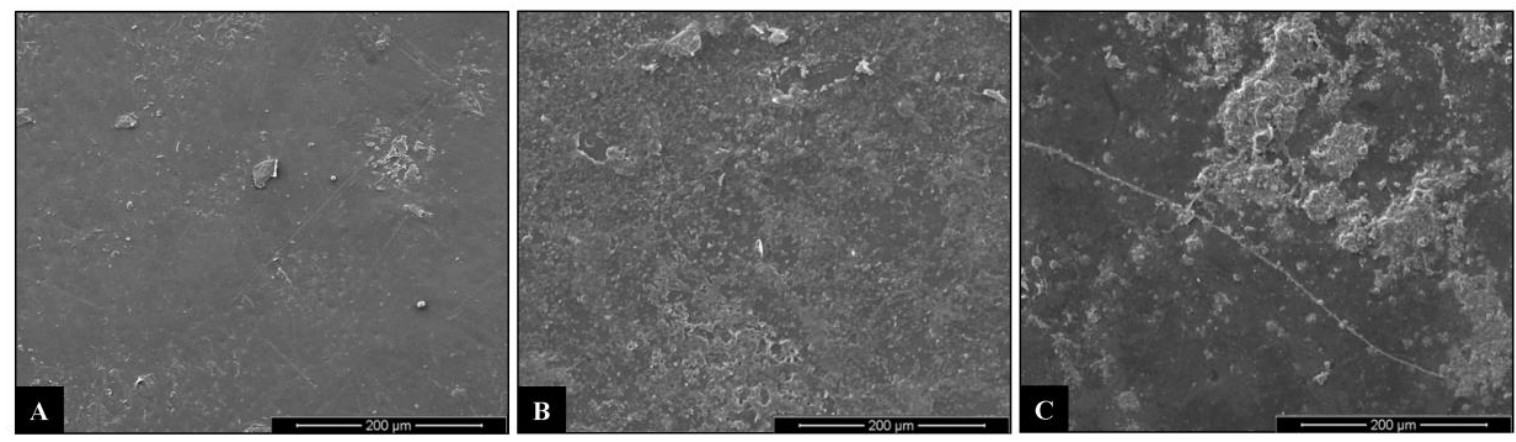

Figure 6. SEM micrographs with a magnification of 1,000x of PLA/PBAT films: at the initial time (A), after biodegradation in soil (B), and in an aqueous medium (C) for 180 days.

\section{Funding}

This research was funded by FUNDAÇÃO DE AMPARO À PESQUISA DO ESTADO DE SÃO PAULO (FAPESP), grant numbers 2017/11386-8 and 2017/24873-4.

\section{Acknowledgments}

This research has no acknowledgment.

\section{Conflicts of Interest}

The authors declare no conflict of interest.

\section{References}

1. Hernández-López, M.; Correa-Pacheco, Z.N.; Bautista-Baños, S.; Zavaleta-Avejar, L.; Benítez-Jiménez, J.J.; Sabino-Gutiérrez, M.A.; Ortega-Gudiño, P. Bio-based composite fibers from pine essential oil and PLA/PBAT polymer blend. Morphological, physicochemical, thermal and mechanical characterization. Materials Chemistry and Physics 2019, 234, 345-353, https://doi.org/10.1016/j.matchemphys.2019.01.034.

2. Zhong, Y.; Godwin, P.; Jin, Y.; Xiao, H. Biodegradable polymers and green-based antimicrobial packaging materials: A mini-review. Advanced Industrial and Engineering Polymer Research 2020, 3, 27-35, https://doi.org/10.1016/j.aiepr.2019.11.002.

3. Martínez-Camacho, A.P.; Cortez-Rocha, M.O.; Graciano-Verdugo, A.Z.; Rodríguez-Félix, F.; CastilloOrtega, M.M.; Burgos-Hernández, A.; Ezquerra-Brauer, J.M.; Plascencia-Jatomea, M. Extruded films of blended chitosan, low density polyethylene and ethylene acrylic acid. Carbohydrate Polymers 2013, 91, 666-674, https://doi.org/10.1016/j.carbpol.2012.08.076.

4. Gupta, S.; Mohan, K.; Prasad, R.; Gupta, S.; Kansal, A. Solid waste management in India: options and opportunities. Resources, Conservation and Recycling 1998, 24, 137-154, https://doi.org/10.1016/S09213449(98)00033-0.

5. Mor, S.; Ravindra, K.; De Visscher, A.; Dahiya, R.P.; Chandra, A. Municipal solid waste characterization and its assessment for potential methane generation: A case study. Science of The Total Environment 2006, 371, 1-10, https://doi.org/10.1016/j.scitotenv.2006.04.014.

6. Azzarello, M.Y.; Van Vleet, E.S.; Public Interest Research Centre.; Pollution, M.P.; Safety, S.; Windsor, F.M.; Durance, I.; Horton, A.A.; Thompson, R.C.; Tyler, C.R.; Ormerod, S.J.; Hamer, G.; Pardini, K.; Rodrigues, J.J.P.C.; Kozlov, S.A.; Kumar, N.; Furtado, V.; Wilcox, C.; Van Sebille, E.; Hardesty, B.D. Public Interest Research Centre A guide to how words can help wildlife. Environ Monit Assess 2019, 37. 
7. Singh, A. Groundwater resources management through the applications of simulation modeling: A review. Science of The Total Environment 2014, 499, 414-423, https://doi.org/10.1016/j.scitotenv.2014.05.048.

8. Singh, A. Simulation and Optimization Modeling for the Management of Groundwater Resources. I: Distinct Applications. Journal of Irrigation and Drainage Engineering 2014, 140, 1-10, https://doi.org/10.1061/(ASCE)IR.1943-4774.0000688.

9. Singh, A. Simulation and Optimization Modeling for the Management of Groundwater Resources. II: Combined Applications. Journal of Irrigation and Drainage Engineering 2014, 140, 1-9, https://doi.org/10.1061/(ASCE)IR.1943-4774.0000689.

10. Larrañaga, A.; Lizundia, E. A review on the thermomechanical properties and biodegradation behaviour of polyesters. European Polymer Journal 2019, 121, https://doi.org/10.1016/j.eurpolymj.2019.109296.

11. ASTM D6813, ASTM 6813: Standard Guide for Performance Evaluation of Hydrulic Fluids fir Piston Pumps, 2019.

12. European Bioplastics nova-I, Bioplastics market data 2019 - Global production capacities of bioplastics 2019-2024, 2019.

13. Armentano, I.; Bitinis, N.; Fortunati, E.; Mattioli, S.; Rescignano, N.; Verdejo, R.; Lopez-Manchado, M.A.; Kenny, J.M. Multifunctional nanostructured PLA materials for packaging and tissue engineering. Progress in Polymer Science 2013, 38, 1720-1747, https://doi.org/10.1016/j.progpolymsci.2013.05.010.

14. Elsawy, M.A.; Kim, K.-H.; Park, J.-W.; Deep, A. Hydrolytic degradation of polylactic acid (PLA) and its composites. Renewable and Sustainable Energy Reviews 2017, 79, 1346-1352, https://doi.org/10.1016/j.rser.2017.05.143.

15. Farah, S.; Anderson, D.G.; Langer, R. Physical and mechanical properties of PLA, and their functions in widespread applications - A comprehensive review. Advanced Drug Delivery Reviews 2016, 107, 367-392, https://doi.org/10.1016/j.addr.2016.06.012.

16. Rasal, R.M.; Janorkar, A.V.; Hirt, D.E. Poly(lactic acid) modifications. Progress in Polymer Science 2010, 35, 338-356, https://doi.org/10.1016/j.progpolymsci.2009.12.003.

17. Sun, H.; Yang, Z.; Yang, F.; Wu, W.; Wang, J. Enhanced simultaneous nitrification and denitrification performance in a fixed-bed system packed with PHBV/PLA blends. International Biodeterioration \& Biodegradation 2020, 146, https://doi.org/10.1016/j.ibiod.2019.104810.

18. Kalita, N.K.; Bhasney, S.M.; Mudenur, C.; Kalamdhad, A.; Katiyar, V. End-of-life evaluation and biodegradation of Poly(lactic acid) (PLA)/Polycaprolactone (PCL)/Microcrystalline cellulose (MCC) polyblends under composting conditions. Chemosphere 2020, https://doi.org/10.1016/j.chemosphere.2020.125875.

19. Mohandesnezhad, S.; Pilehvar-Soltanahmadi, Y.; Alizadeh, E.; Goodarzi, A.; Davaran, S.; Khatamian, M.; Zarghami, N.; Samiei, M.; Aghazadeh, M.; Akbarzadeh, A. In vitro evaluation of Zeolite-nHA blended PCL/PLA nanofibers for dental tissue engineering. Materials Chemistry and Physics 2020, 252, https://doi.org/10.1016/j.matchemphys.2020.123152.

20. Xiang, S.; Feng, L.; Bian, X.; Li, G.; Chen, X. Evaluation of PLA content in PLA/PBAT blends using TGA. Polymer Testing 2020, 81, https://doi.org/10.1016/j.polymertesting.2019.106211.

21. Qiu, S.; Zhou, Y.; Waterhouse, G.I.N.; Gong, R.; Xie, J.; Zhang, K.; Xu, J. Optimizing interfacial adhesion in PBAT/PLA nanocomposite for biodegradable packaging films. Food Chemistry 2021, 334, https://doi.org/10.1016/j.foodchem.2020.127487.

22. Jiang, L.; Wolcott, M.P.; Zhang, J. Study of Biodegradable Polylactide/Poly(butylene adipate-coterephthalate) Blends. Biomacromolecules 2006, 7, 199-207, https://doi.org/10.1021/bm050581q.

23. Zhang, M.; Jia, H.; Weng, Y.; Li, C. Biodegradable PLA/PBAT mulch on microbial community structure in different soils. International Biodeterioration \& Biodegradation 2019, 145, https://doi.org/10.1016/j.ibiod.2019.104817.

24. Jian, J.; Xiangbin, Z.; Xianbo, H. An overview on synthesis, properties and applications of poly(butyleneadipate-co-terephthalate)-PBAT. Advanced Industrial and Engineering Polymer Research 2020, 3, 19-26, https://doi.org/10.1016/j.aiepr.2020.01.001.

25. RameshKumar, S.; Shaiju, P.; O’Connor, K.E.; P, R.B. Bio-based and biodegradable polymers - State-ofthe-art, challenges and emerging trends. Current Opinion in Green and Sustainable Chemistry 2020, $21,75-$ 81, https://doi.org/10.1016/j.cogsc.2019.12.005.

26. Ferreira, F.V.; Cividanes, L.S.; Gouveia, R.F.; Lona, L.M.F. An overview on properties and applications of poly(butylene adipate-co-terephthalate)-PBAT based composites. Polymer Engineering \& Science 2019, 59, E7-E15, https://doi.org/10.1002/pen.24770.

27. Nagarajan, V.; Misra, M.; Mohanty, A.K. New engineered biocomposites from poly (3-hydroxybutyrate-co3-hydroxyvalerate)(PHBV)/poly (butylene adipate-co-terephthalate)(PBAT) blends and switchgrass: Fabrication and performance evaluation. Industrial crops and products 2013, 42, 461-468.

28. Gigante, V.; Canesi, I.; Cinelli, P.; Coltelli, M.B.; Lazzeri, A. Rubber Toughening of Polylactic Acid (PLA) with Poly(butylene adipate-co-terephthalate) (PBAT): Mechanical Properties, Fracture Mechanics and Analysis of Ductile-to-Brittle Behavior while Varying Temperature and Test Speed. European Polymer Journal 2019, 115, 125-137, https://doi.org/10.1016/j.eurpolymj.2019.03.015. 
29. Qi, X.; Ren, Y.; Wang, X. New advances in the biodegradation of Poly(lactic) acid. International Biodeterioration \& Biodegradation 2017, 117, 215-223, https://doi.org/10.1016/j.ibiod.2017.01.010.

30. Rudnik, E.; Briassoulis, D. Comparative Biodegradation in Soil Behaviour of two Biodegradable Polymers Based on Renewable Resources. Journal of Polymers and the Environment 2011, 19, 18-39, https://doi.org/10.1007/s10924-010-0243-7.

31. Tokiwa, Y.; Calabia, B.P. Biodegradability and biodegradation of poly(lactide). Applied Microbiology and Biotechnology 2006, 72, 244-251, https://doi.org/10.1007/s00253-006-0488-1.

32. Tokiwa, Y.; Calabia, B.P. Biodegradability and Biodegradation of Polyesters. Journal of Polymers and the Environment 2007, 15, 259-267, https://doi.org/10.1007/s10924-007-0066-3.

33. Rudnik, E.; Briassoulis, D. Degradation behaviour of poly(lactic acid) films and fibres in soil under Mediterranean field conditions and laboratory simulations testing. Industrial Crops and Products 2011, 33, 648-658, https://doi.org/10.1016/j.indcrop.2010.12.031.

34. Cadar, O.; Paul, M.; Roman, C.; Miclean, M.; Majdik, C. Biodegradation behaviour of poly(lactic acid) and (lactic acid-ethylene glycol-malonic or succinic acid) copolymers under controlled composting conditions in a laboratory test system. Polymer Degradation and Stability 2012, 97, 354-357, https://doi.org/10.1016/j.polymdegradstab.2011.12.006.

35. Tabasi, R.Y.; Ajji, A. Selective degradation of biodegradable blends in simulated laboratory composting. $\begin{array}{llllll}\text { Polymer Degradation } & \text { and } & \text { Stability } & \mathbf{2 0 1 5}, & 120, & 435-442 \text {, }\end{array}$ https://doi.org/10.1016/j.polymdegradstab.2015.07.020.

36. Weng, Y.-X.; Jin, Y.-J.; Meng, Q.-Y.; Wang, L.; Zhang, M.; Wang, Y.-Z. Biodegradation behavior of poly(butylene adipate-co-terephthalate) (PBAT), poly(lactic acid) (PLA), and their blend under soil conditions. Polymer Testing 2013, 32, 918-926, https://doi.org/10.1016/j.polymertesting.2013.05.001.

37. Pischedda, A.; Tosin, M.; Degli-Innocenti, F. Biodegradation of plastics in soil: The effect of temperature. Polymer Degradation and Stability 2019, 170, https://doi.org/10.1016/j.polymdegradstab.2019.109017.

38. Kalita, N.K.; Nagar, M.K.; Mudenur, C.; Kalamdhad, A.; Katiyar, V. Biodegradation of modified Poly(lactic acid) based biocomposite films under thermophilic composting conditions. Polymer Testing 2019, 76, 522536, https://doi.org/10.1016/j.polymertesting.2019.02.021.

39. Leejarkpai, T.; Suwanmanee, U.; Rudeekit, Y.; Mungcharoen, T. Biodegradable kinetics of plastics under controlled composting conditions. Waste Management 2011, 31, 1153-1161, https://doi.org/10.1016/j.wasman.2010.12.011.

40. Kijchavengkul, T.; Auras, R.; Rubino, M.; Selke, S.; Ngouajio, M.; Fernandez, R.T. Biodegradation and hydrolysis rate of aliphatic aromatic polyester. Polymer Degradation and Stability 2010, 95, 2641-2647, https://doi.org/10.1016/j.polymdegradstab.2010.07.018.

41. Bonilla, J.; Paiano, R.B.; Lourenço, R.V.; Bittante, A.M.Q.B.; Sobral, P.J.A. Biodegradability in aquatic system of thin materials based on chitosan, PBAT and HDPE polymers: Respirometric and physicalchemical analysis. International Journal of Biological Macromolecules 2020, 164, 1399-1412, https://doi.org/10.1016/j.ijbiomac.2020.07.309.

42. Freitas, A.L.P.d.L.; Tonini Filho, L.R.; Calvão, P.S.; Souza, A.M.C.d. Effect of montmorillonite and chain extender on rheological, morphological and biodegradation behavior of PLA/PBAT blends. Polymer Testing 2017, 62, 189-195, https://doi.org/10.1016/j.polymertesting.2017.06.030.

43. Palsikowski, P.A.; Kuchnier, C.N.; Pinheiro, I.F.; Morales, A.R. Biodegradation in Soil of PLA/PBAT Blends Compatibilized with Chain Extender. Journal of Polymers and the Environment 2018, 26, 330-341, https://doi.org/10.1007/s10924-017-0951-3.

44. Braga, N.; Silva, A.P.; Arantes, T.; Lemes, A.; Cristovan, F. Physical-chemical properties of nanocomposites based on poly(3-hydroxybutyrate-co-3-hydroxyvalerate) and titanium dioxide nanoparticles. Materials Research Express 2017, 5, https://doi.org/10.1088/2053-1591/aa9f7a.

45. Wing Hong, L.; Yu, J. Environmental factors and kinetics of microbial degradation of poly(3hydroxybutyrate-co-3-hydroxyvalerate) in an aqueous medium. Journal of Applied Polymer Science 2003, 87, 205-213, https://doi.org/10.1002/app.11354.

46. da Silva, A.P.; do Amaral Montanheiro, T.L.; Stieven Montagna, L.; Andrade, P.F.; Durán, N.; Lemes, A.P. Effect of carbon nanotubes on the biodegradability of poly(3-hydroxybutyrate-co-3-hydroxyvalerate) nanocomposites. Journal of Applied Polymer Science 2019, 136, 1-10, https://doi.org/10.1002/app.48020.

47. Cardoso, E.C.L.; Scagliusi, S.R.; Lugão, A.B. Gamma-Radiation Effect on Biodegradability of Synthetic PLA Structural Foams PP/HMSPP Based. In: Proceedings of Characterization of Minerals, Metals, and Materials 2017. Cham, 2017; pp. 111-119.

48. ASTM D6400, ASTM D6400 - 19: Standard Specification for Labeling of Plastics Designed to be Aerobically Composted in Municipal or Industrial Facilities, 2019.

49. Rydz, J.; Adamus, G.; Wolna-Stypka, K.; Marcinkowski, A.; Misiurska-Marczak, M.; Kowalczuk, M.M. Degradation of polylactide in paraffin and selected protic media. Polymer Degradation and Stability 2013, 98, 316-324, https://doi.org/10.1016/j.polymdegradstab.2012.09.010.

50. Musioł, M.; Sikorska, W.; Janeczek, H.; Wałach, W.; Hercog, A.; Johnston, B.; Rydz, J. (Bio)degradable polymeric materials for a sustainable future - part 1 . Organic recycling of PLA/PBAT blends in the form of 
prototype packages with long shelf-life. Waste Management 2018, 77, 447-454, https://doi.org/10.1016/j.wasman.2018.04.030.

51. ASTM D5338, ASTM D5338-15 : Standard Test Method for Determining Aerobic Biodegradation of Plastic Materials Under Controlled Composting Conditions, Conditions, Incorporating Thermophilic Temperatures, 2015.

52. Kale, G.; Auras, R.; Singh, S.P. Comparison of the degradability of poly(lactide) packages in composting and ambient exposure conditions. Packaging Technology and Science 2007, 20, 49-70, https://doi.org/10.1002/pts.742.

53. Araújo, A.; Botelho, G.; Oliveira, M.; Machado, A.V. Influence of clay organic modifier on the thermalstability of PLA based nanocomposites. Applied Clay Science 2014, 88-89, 144-150, https://doi.org/10.1016/j.clay.2013.12.005.

54. Jayasekara, R.; Harding, I.; Bowater, I.; Lonergan, G. Biodegradability of a Selected Range of Polymers and Polymer Blends and Standard Methods for Assessment of Biodegradation. Journal of Polymers and the Environment 2005, 13, 231-251, https://doi.org/10.1007/s10924-005-4758-2.

55. Soria, J.; Sanz, J.; Sobrados, I.; Coronado, J.M.; Maira, A.J.; Hernández-Alonso, M.D.; Fresno, F. FTIR and NMR Study of the Adsorbed Water on Nanocrystalline Anatase. The Journal of Physical Chemistry C 2007, 111, 10590-10596, https://doi.org/10.1021/jp071440g.

56. Ji, S.; Jiang, T.; Xu, K.; Li, S. FTIR study of the adsorption of water on ultradispersed diamond powder surface. Applied Surface Science 1998, 133, 231-238, https://doi.org/10.1016/S0169-4332(98)00209-8.

57. Guo, X.; Yuan, H.; Xiao, T.; Wu, Y. Application of micro-FTIR spectroscopy to study molecular association of adsorbed water with lignin. International Journal of Biological Macromolecules 2019, 131, 1038-1043, https://doi.org/10.1016/j.ijbiomac.2019.03.193.

58. Zhou, Y.; Lei, L.; Yang, B.; Li, J.; Ren, J. Preparation and characterization of polylactic acid (PLA) carbon nanotube nanocomposites. Polymer Testing https://doi.org/10.1016/j.polymertesting.2018.03.044.

59. Sharif, F.; Tabassum, S.; Mustafa, W.; Asif, A.; Zarif, F.; Tariq, M.; Siddiqui, S.A.; Gilani, M.A.; Ur Rehman, I.; MacNeil, S. Bioresorbable antibacterial PCL-PLA-nHA composite membranes for oral and maxillofacial defects. Polymer Composites 2019, 40, 1564-1575, https://doi.org/10.1002/pc.24899.

60. Johnson, P.; Routledge, T.; Trybala, A.; Vaccaro, M.; Starov, V. Wetting and Spreading of Commercially Available Aqueous Surfactants on Porous Materials. Colloids and Interfaces 2019, 3, 1-9, https://doi.org/10.3390/colloids3010014.

61. Zisman, W.A. Relation of the Equilibrium Contact Angle to Liquid and Solid Constitution. In: Meetíng of the American Chemical Societty. Contact Angle:Wettability and Adhesion. 1964; pp. 1-51.

62. Schusser, S.; Menzel, S.; Bäcker, M.; Leinhos, M.; Poghossian, A.; Wagner, P.; Schöning, M.J. Degradation of thin poly(lactic acid) films: Characterization by capacitance-voltage, atomic force microscopy, scanning electron microscopy and contact-angle measurements. Electrochimica Acta 2013, 113, 779-784, https://doi.org/10.1016/j.electacta.2013.08.025.

63. Dou, Q.; Cai, J. Investigation on Polylactide (PLA)/Poly(butylene adipate-co-terephthalate) (PBAT)/Bark Flour of Plane Tree (PF) Eco-Composites. Materials 2016, 9, https://doi.org/10.3390/ma9050393.

64. Stieven Montagna, L.; Amaral Montanheiro, T.L.d.; Chiodi Borges, A.; Yumi Koga-Ito, C.; Paula Lemes, A.; Cerqueira Rezende, M. Biodegradation of PHBV/GNS nanocomposites by Penicillium funiculosum. Journal of Applied Polymer Science 2017, 134,1-8, https://doi.org/10.1002/app.44234.

65. Silva, T.F.D.; Menezes, F.; Montagna, L.S.; Lemes, A.P.; Passador, F.R. Preparation and characterization of antistatic packaging for electronic components based on poly(lactic acid)/carbon black composites. Journal of Applied Polymer Science 2019, 136, 1-8, https://doi.org/10.1002/app.47273.

66. Olewnik-Kruszkowska, E.; Burkowska-But, A.; Tarach, I.; Walczak, M.; Jakubowska, E. Biodegradation of polylactide-based composites with an addition of a compatibilizing agent in different environments. International Biodeterioration \& Biodegradation 2020, 147, https://doi.org/10.1016/j.ibiod.2019.104840.

67. Moura I, Machado A V., Duarte FM, Nogueira R (2010) Biodegradability Assessment of Aliphatic Polyesters-Based Blends Using Standard Methods. J Appl Polym Sci 119:3338-3346 https://doi.org/10.1002/app

68. Sánchez C (2020) Fungal potential for the degradation of petroleum-based polymers: An overview of macroand microplastics biodegradation. Biotechnol Adv 40:107501 https://doi.org/10.1016/j.biotechadv.2019.107501 